\title{
Natural and Artificial Weathering of B.mori Silk Fabric
}

\author{
Jinfa Ming ${ }^{1,2, a}$, Yaoxing Jiang ${ }^{1,2, b^{*}}$ and Baoqi Zuo ${ }^{1,2, c^{*}}$ \\ ${ }^{1}$ National Engineering Laboratory for Modern Silk, Soochow University, Suzhou, 215123, China \\ ${ }^{2}$ College of Textile and Clothing Engineering, Soochow University, Suzhou, 215021, China \\ ajinfa.ming@gmail.com, bjiangyaoxing@suda.edu.cn, cbqzuo@suda.edu.cn
}

Keywords: B.mori Silk, Artificial Weathering, Yellowness Index, Mechanical Properties.

\begin{abstract}
Ultraviolet aging of B.mori silk fabric was studied under natural and artificial weathering conditions. Exposed samples were removed periodically and characterized by several analytical techniques. During both types of weathering, the results showed that yellowness index presented a rising trend with the extension of aging time; breaking strength of B.mori silk fabric decreased approximately $93.62 \%, 43.30 \%$ under natural aging 150 days and artificial accelerated aging $80 \mathrm{~h}$, respectively; the peak intensity of amide I, and amide II, etc. significantly declined, even disappeared. At the same time, the conformation transition of B.mori silk was from random coil to $\beta$-pleated sheet following the prolonging of ultraviolet aging time. What's more, the content of amino acid obviously declined especially histidine, tyrosine, and lysine etc. In addition, the results evidenced that during natural and artificial weathering, various performances of B.mori silk fabric changed similarly. So artificial weathering can be used to substitute for natural weathering for its weathering evaluation, which is helpful to understand the aging behavior and take measures to avoid aging and elongate its service life.
\end{abstract}

\section{Introduction}

B.mori silk is one of the most precious raw materials of natural origin employed in manufacturing textile products owing to its outstanding characteristics, such as its luster, comfort, high moisture regain, and high specific strength etc. [1-4]. Therefore, B.mori silk fabric becomes one of the most important costume fabrics. It is used for all kinds of outdoor public place, where good resistance to ultraviolet (UV) radiation is required. UV radiation is one of the major causes of natural aging of textile materials [5], especially B.mori silk fiber easily happening aging phenomenon, resulting in yellowing and other properties loss, such as luster, mechanical property, thermal property, and amino acid contents, etc.

Under weathering conditions, there are several factors that can be result in B.mori silk aging, namely external causes related with environmental conditions (light sources and their spectral distribution such as UV radiation, oxygen, relative humidity, temperature and various impurities in atmosphere) [6-7] and inherent features (molecular structure, molecular chain scission and recombination, crystallinity, and amino acid contents, etc.) [8-9].

Most of the scientific research until now, on photo-oxidation and photochemical processes occurring during B.mori silk aging, was performed under natural and artificial weathering conditions [10-13]. The development of methods allowing acceleration of the UV aging processes during B.mori silk fabric lifetime was considered very important. Several equipments have been used in artificial accelerated aging tests (YG(B) 611 type insolation climate tester, Altas weathering equipments series, etc.) to predict the B.mori silk fabric lifetime under service conditions. The correlation between natural and artificial weathering is not trivial and depend on many influence factors, such as accelerated weathering devices, light source in accelerated aging, geographical localization in natural experiments, temperature, and amount of sunshine hours, mechanical stresses, biological attack, and environmental contaminants [6]. 
It is known that a good correlation between different weathering devices is found when the equipment operates with the same type of radiation source and under similar conditions, being the temperature an important parameter [6,14-18].

Up to now, lots of studies on B.mori silk aging have been performed under artificial accelerated conditions [19-21], this is essential to reproduce the natural weathering phenomena to evaluate the real durability of B.mori silk. However, the influence of UV irradiation on B.mori silk fabric has been poorly investigated so far. The aim of our work is to research and compare the UV aging behaviour of B.mori silk fabric during natural and artificial weathering conditions. B.mori silk fabric samples were submitted to natural and artificial weathering. Experiments were carried out to study and analysis the details on the influence of UV irradiation on chemical structure and physical properties.

\section{Experimental}

Material. The used type of B.mori silk fabric was plain habutai, which was bought from Jiangsu province of China. The specifications of B.mori silk fabric was as follows: warp linear density, 3.18 tex; weft linear density, 5.34 tex; warp and weft density, $616 \times 400$ roots $/ 10 \mathrm{~cm}$.

Sample Preparation. B.mori silk fabric was washed in deionized water and dried with static air at the room temperature. Later, in the following experiments B.mori silk fabric was cut according to required dimensions and submitted to natural and artificial weathering, in agreement to standard methods.

Natural Weathering. The natural weathering was performed during six months in Soochow University (Suzhou, China) which located in north subtropical moist monsoon climate zone. Samples obtained under the same processing conditions as stated before, were placed in a wood support, at an angle of $45^{\circ}$, facing south [22]. Total exposure period was six months starting from March 2010. The average outdoor temperature was provided by Suzhou meteorological bureau website, being $9.1{ }^{\circ} \mathrm{C}$, $13.3{ }^{\circ} \mathrm{C}, 20.8{ }^{\circ} \mathrm{C}, 24.3{ }^{\circ} \mathrm{C}, 28.6{ }^{\circ} \mathrm{C}$, and $31.3{ }^{\circ} \mathrm{C}$ in March, April, May, June, July, and August, respectively. In addition, Table 1 shows more details related to relative humidity, UV exposure etc. during outdoor experiments.

Table 1 Environmental condition in natural weathering experiments (average values)

\begin{tabular}{ccccc}
\hline Month & $\begin{array}{c}\text { Relative humidity } \\
(\%)\end{array}$ & $\begin{array}{c}\text { Wind velocity } \\
(\mathrm{m} / \mathrm{s})\end{array}$ & $\begin{array}{c}\text { UV radiation } \\
\left(\mathrm{uW} / \mathrm{cm}^{2}\right)\end{array}$ & $\begin{array}{c}\text { UV exposure } \\
\text { (hour) }\end{array}$ \\
\hline March & 59.5 & 2.47 & 1280.1 & 91.5 \\
April & 55.6 & 2.19 & 1881.8 & 124.0 \\
May & 54.5 & 2.72 & 1928.8 & 152.6 \\
June & 59.6 & 1.99 & 1839.3 & 106.7 \\
July & 65.5 & 2.74 & 2984.2 & 165.4 \\
August & 50.8 & 2.84 & 3375.7 & 250.0 \\
\hline
\end{tabular}

B.mori silk fabric samples were removed periodically and characterized by several analytical techniques.

Artificial Weathering. The artificial accelerated weathering was carried out in a Xenotest YG(B)611-IV chamber from Wenzhou DaRong Textile Instrument Co. LTD (Zhejiang province, China) equipped with a filtered Xenon lamp according to standard procedures [23].

During $2 \mathrm{~h}$ of aging cycle, the samples $(115 \mathrm{~mm} \times 45 \mathrm{~mm})$, cuted from the B.mori silk fabric, were exposed to different UV aging time period. In the UV aging process, experimental parameters were respectively as follows: Temperature, $35^{\circ} \mathrm{C}$; Relative humidity, $40 \%$; UV irradiation intensity, 1.10 $\mathrm{W} / \mathrm{m}^{2} / \mathrm{nm}$. 


\section{Characterization}

Yellowness Index Measurement. Yellowness index for all the different natural and artificial accelerated weathering samples were measured using U-3010 UV spectrophotometer of Hitachi. During the test, the parameter of scan wavelength was from $600.00 \mathrm{~nm}$ to $200.00 \mathrm{~nm}$. In the end, each sample was tested five times, and then, calculating the average value. Yellowness index was calculated as follows:

$$
Y I / \%=\frac{R_{600}-R_{425}}{R_{555}} \times 100
$$

Mechanical Testing. The mechanical properties of B.mori silk fabric unexposed and submitted to natural and artificial weathering were characterized using an automatic tensile tester (model 3365 electronic strength tester; Instron, Boston, USA). These samples were kept for $24 \mathrm{~h}$ at standard atmospheric conditions $\left(20^{\circ} \mathrm{C}\right.$ and $\left.65 \% \mathrm{RH}\right)$ before the mechanical test. Distance between grips and test speeds were set to $30 \mathrm{~mm}$ and $20 \mathrm{~mm} / \mathrm{min}$, respectively. At the same time, the pre-tension was 0.2 $\mathrm{cN}$. In addition, each sample was tested twenty times and the average values of test results were calculated.

FT-IR Spectroscopy. The spectrograms of the surface of B.mori silk fabric samples were tested by using Nicolet5700 (Thermo Nicolet Company, USA). Each spectrum was obtained by the performance of 32 scans between $4000 \mathrm{~cm}^{-1}$ and $400 \mathrm{~cm}^{-1}$ at intervals of $1 \mathrm{~cm}^{-1}$ with a resolution of 4 $\mathrm{cm}^{-1}$. FTIR spectroscopic study was performed to assess the structural degradation of the samples or to determine if there is a change in the chemical structure, when samples were irradiated under natural and artificial weathering, respectively.

Thermal Analysis. Thermal analysis was carried out using SDT Q600 simultaneous thermal analysis instrument of American TA Company, under a constant nitrogen flow $100.0 \mathrm{ml} / \mathrm{min}$. The samples were heated from $50.00{ }^{\circ} \mathrm{C}$ to $600{ }^{\circ} \mathrm{C}$ using a heat rate of $10.00{ }^{\circ} \mathrm{C} / \mathrm{min}$. The B.mori silk fabric unexposed and submitted to natural and artificial weathering samples were tested.

Amino Acid Analysis. Samples unexposed and exposed to different UV aging time were hydrolyzed using hydrochloric acid $(6 \mathrm{~mol} / \mathrm{L}, 5 \mathrm{~mL})$. And then amino acid analysis was performed on model L-8900 Amino Acid Analyzer (Hitachi, Japan).

\section{Results and Discussion}

Yellowness Index Analysis. Yellowness of B.mori silk fabric formed after natural and artificial weathering is due to the B.mori silk fabric surface aging. Figure 1 depicts the yellowness index of B.mori silk fabric samples submitted to natural and artificial weathering, respectively. Figure 1(a) shows that yellowness index of unexposed samples are $-2.12 \%$. In the period of aging time, yellowness index of the samples exposed to natural aging increases until 150 days, the yellowness index is obtained, reaching approximately $30.49 \%$. At the same time, during the artificial accelerated aging $80 \mathrm{~h}$, yellowness index of B.mori silk fabric reaches $6.96 \%$ in Figure 1(b). In addition, after 150 days of natural weathering and $80 \mathrm{~h}$ of artificial weathering, the variation tendency of yellowness index is similar, namely: the yellowness index of B.mori silk fabric surface appears obviously rising trend within the natural and artificial weathering aging process. Thus it can be seen that yellowness index has part correlated with B.mori silk absorbing UV radiation.
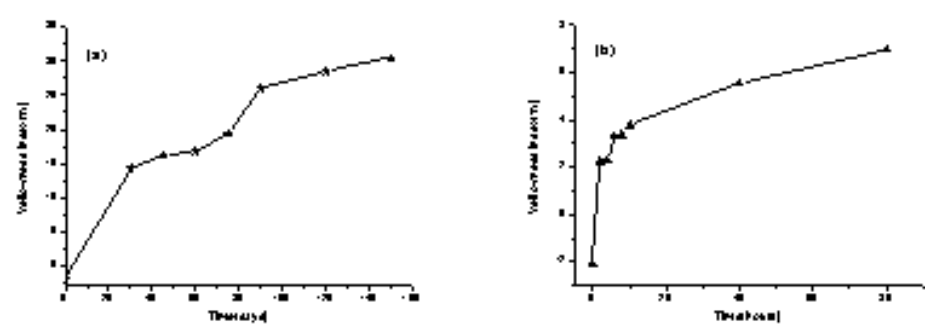

Figure 1 Yellowness index of B.mori silk fabric submitted to natural and artificial weathering

(a) natural weathering; (b) artificial weathering 
In addition, we consider that the yellowness index of B.mori silk fabric submitted to irradiation in the presence of oxygen is due to photo-oxidation reaction of silk. Stela, etc.[24] confirmed the photo-oxidation of natural silk happening. In the photo-oxidation process, the increase of the amount of carbonyl groups during irradiation proves that they are the main products formed. Therefore, the main photodestructive reaction in fibroin is preceded by the formation of $\alpha$ - keto acids at the amino acids glycine and alanine. The same values are also confirmed by Meybeck etc. Besides, Masuhiro, etc.[25] suggested the influence of temperature on silk yellowing is worth noting. With increasing the temperature, it probably resulted in an increase of silk macroradical formation, thereby enhancing silk yellowness.

Mechanical Properties Analysis. It is known that changes in chemical and morphological silk structure are responsible for the deterioration of mechanical properties (mainly breaking strength and elongation at break etc.), disintegration of the silk fiber. To follow the mechanical behavior, breaking strength curves are obtained using B.mori silk fabric with different exposure time under natural and artificial weathering conditions. The results are shown in Figure 2.
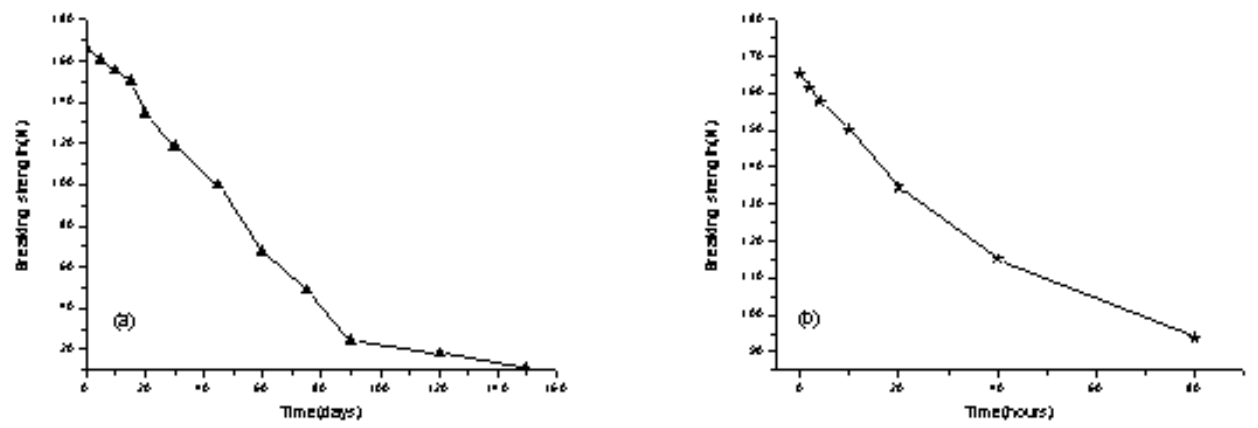

Figure 2 Breaking strength trend of B.mori silk fabric exposed to natural and artificial weathering

(a) natural weathering; (b) artificial weathering

From Figure 2, clear aging effect is observed on the breaking strength curves, which shows a large reduction after a few days (natural weathering) or some hours (artificial weathering). Under natural weathering condition, the breaking strength of B.mori silk fabric is $59.36 \%$ after natural aging 60 days. Until natural aging 150 days, the breaking strength of B.mori silk fabric reduces to $6.38 \%$ level of initial values of breaking strength. Whereas B.mori silk fabric submitted to artificial weathering decreases approximately $43.30 \%$ of breaking strength after $80 \mathrm{~h}$ of artificial weathering exposure. Because breaking strength is used as an obvious indicator of the textile material aging. If the initial value of breaking strength decreases $50 \%$, B.mori silk fabric is considered not suitable for any application. It is clear that B.mori silk fabric exposed to natural weathering 60 days or artificial weathering $80 \mathrm{~h}$ can be lost its application values.

The difference between natural and artificial weathering results can be explained taking into account the different environmental parameters present in each of aging condition. For one thing, aging is a phenomenon that occurs at the fabric surface. The UV irradiation leads to fiber breakage in the sample surface and, consequently, there is loss in mechanical properties especially in breaking strength. On the other hand, natural weathering seems to be extremely influenced by high relative humidity, rain and several other factors that are not present in accelerated equipment, such as, atmospheric pollutants (ozone, smoke, sulfur dioxide, and nitrogen oxides etc.), and mechanical stress (related to wind etc.).

FT-IR Analysis. In order to better explain the mechanical properties degradation observed previously (Figure 2), a microstructure characterization of the aged B.mori silk submitted to natural and artificial weathering has been investigated through FTIR analysis with reflectance mode. As follows, the infrared absorption spectra of both aged and unaged samples acquired in fabric form are shown in Figure 3. 

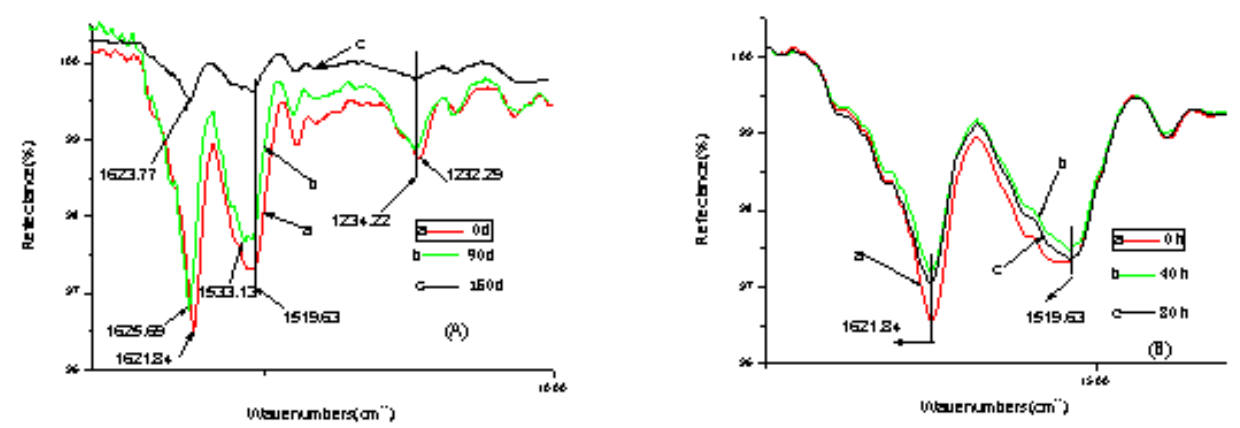

Figure 3 FTIR of B.mori silk submitted to natural and artificial weathering (A) natural weathering; (B) artificial weathering

As it can be seen in Figure 3, the conformation of all the B.mori silk samples (different aging time under natural and artificial weathering) shows mainly $\beta$-pleated sheet. Figure 3 shows the main characteristic peaks of B.mori silk consist of a band $1621 \mathrm{~cm}^{-1}$ assignable to amide $\mathrm{I}(\mathrm{C}=\mathrm{O}$ and $\mathrm{C}-\mathrm{N}$ stretching vibration, etc.), a band $1519 \mathrm{~cm}^{-1}$ belong to amide II (N-H bending deformation and C-N stretching vibration, etc.). In the Figure 3(A) spectra, it shows that the peak of amide I band from unexposed B.mori silk $\left(1621.84 \mathrm{~cm}^{-1}\right)$ increases $3.85 \mathrm{~cm}^{-1}$, when the natural aging time is 90 days; Until 150 days, the characteristic peak of amide I band increases only $1.93 \mathrm{~cm}^{-1}$, at the same time, the peak of amide I intensity significantly declines, even disappears. While the single peak of amide II band is split into two $1533.13 \mathrm{~cm}^{-1}$ (stronger) and $1519.63 \mathrm{~cm}^{-1}$ (weaker) at natural aging time 90 days. In natural aging 150 days, the amide II peak also almost disappears. In addition, the peak of amide III from unaged B.mori silk (1232.29 $\mathrm{cm}^{-1}$ ) increases $1.93 \mathrm{~cm}^{-1}$. In the Figure 3(B) spectra, the location of B.mori silk absorption peaks has almost no change before and after artificial accelerated weathering $80 \mathrm{~h}$, but the main bands including amide I, and amide II, etc. decline in intensity. At the same time, new characteristic absorption peaks can not be observed in the spectrum of the aged B.mori silk.

The major difference between the spectra corresponding to the aged and unaged samples is only their intensity of bands. For instance, the following absorption (corresponding to amide I, amide II, etc.) intensity decreases in the UV aging process. The changes in the terms of peak intensity can be considered sufficient to reflect the B.mori silk chain scission and chemical bonds restructuring in new position. Such microstructure changes are certainly attributed to aging effect especially the influence of UV radiation. This result confirms again the mechanical degradation described previously in the mechanical properties analysis summary.

Thermal Analysis. DSC curves of B.mori silk samples submitted to natural weathering are reported in Figure 4. It is shown that curve (a), unaged B.mori silk displayed two endothermic peaks, the first wide (heat flow $-2.044 \mathrm{~mW}$ ) and centered at about $83.99{ }^{\circ} \mathrm{C}$, the second one sharper at $313.44{ }^{\circ} \mathrm{C}$ $(-3.1491 \mathrm{~mW})$, and an small exothermic peak at $71.63{ }^{\circ} \mathrm{C}(-1.8269 \mathrm{~mW})$. In addition, the thermal decomposition temperature was detected at about $280.99^{\circ} \mathrm{C}$ (listed in Table 2 ). The small exothermic peak and the higher temperature endothermic peak could be attributed to the random coil- $\beta$-pleated sheet conformation transition [26-28] and to the thermal degradation of silk molecular chains [29]; the lower temperature endothermic peak was attributed by many authors to the water lost during the DSC test procedure [30-31].

As reported in Figure 4, curve (b), (c), and (d) exposed to natural weathering 30 days, 90 days, and 150 days, respectively. These curves have a clearly common characteristic, namely a high temperature endothermic peak locating $317.78{ }^{\circ} \mathrm{C}, 310.44{ }^{\circ} \mathrm{C}$, and $306.61{ }^{\circ} \mathrm{C}$, respectively. This high temperature endothermic peak suggests the UV aging of B.mori silk with the $\beta$-pleated sheet conformation form.

DSC curves of B.mori silk exposed in artificial weathering conditions are shown in Figure 5. It is shown that curve (a), unaged B.mori silk displayed an small exothermic peak at about $71.63{ }^{\circ} \mathrm{C}$. However, when artificial accelerated aging time is $10 \mathrm{~h}, 20 \mathrm{~h}$, and $80 \mathrm{~h}$, respectively, the small exothermic peak isn't obviously even disappear. This could be attributed to the random coil- $\beta$-sheet 
conformational transition [27]. At the same time, curve (a) shows an obviously high temperature endothermic peak at about $313.44{ }^{\circ} \mathrm{C}$. Meanwhile, curve (b), (c) and (d) have also a similarly high temperature endothermic peak, locating $313.69^{\circ} \mathrm{C}, 313.28^{\circ} \mathrm{C}$, and $317.78{ }^{\circ} \mathrm{C}$, respectively.

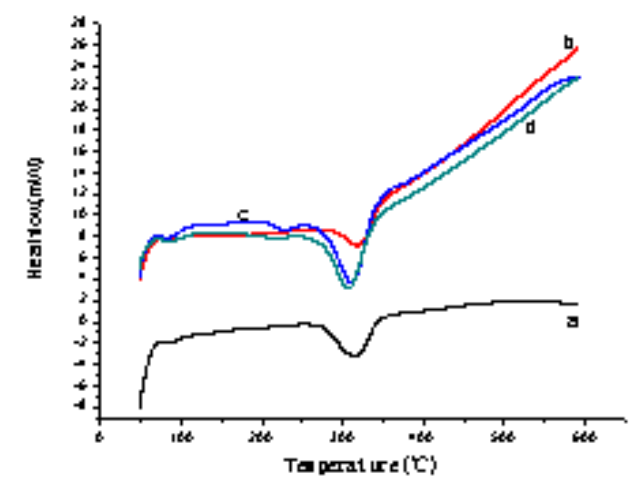

Figure 4 DSC of samples exposed to natural weathering; (a) 0d, (b) 30d, (c) 90d, and (d) 150d

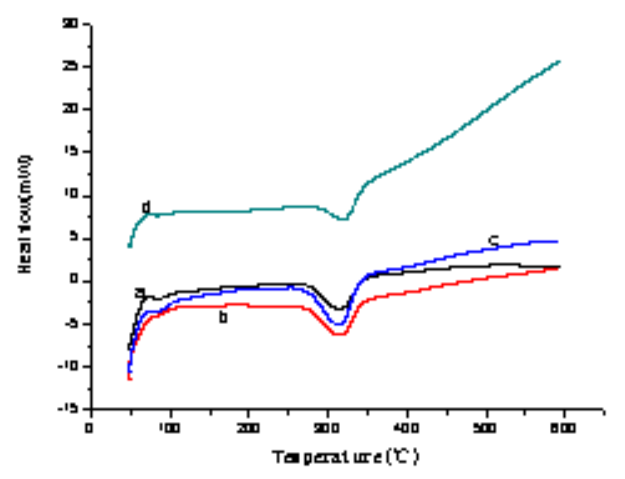

Figure 5 DSC of samples exposed to artificial weathering; (a) 0h, (b) 10h, (c) 20h, and (d) $80 \mathrm{~h}$

In addition, Table 2 shows the values of thermal decomposition temperature obtained for B.mori silk samples exposed to both type of weathering. While the samples exposed to natural weathering during 150 days present a lower value of thermal decomposition temperature of B.mori silk. The downtrend of thermal decomposition temperature is attributed to the aggregation structure of silk fiber changes before and after natural weathering and crystalline degree of its decreases which no longer restricts molecular motions in the amorphous region. Therefore, accompanying with UV energy in fiber internal accumulation, molecular chains of silk fiber are cleavage and the conformation transition of B.mori silk changes. However, the values of thermal decomposition temperature have significantly increased when samples exposed in artificial weathering condition. That is to say, during artificial accelerated $80 \mathrm{~h}$, the UV radiation energy absorbed by B.mori silk induces the changes of thermal decomposition temperature. This demonstrates that the conformation transition of B.mori silk is from random coil to $\beta$-pleated sheet [32]. At the same time, the molecular chemical bonds of B.mori silk would not be significant changes. This result is consistent with the FTIR of B.mori silk exposed in artificial weathering (Figure 3(B)).

Table 2 Thermal decomposition temperatures of unexposed samples and exposed to natural and artificial weathering, respectively

\begin{tabular}{ccc}
\hline Aging & Samples & $\begin{array}{c}\text { Thermal decomposition } \\
\text { temperature }\left({ }^{\circ} \mathrm{C}\right)\end{array}$ \\
\hline unexposed & & 280.99 \\
Natural weathering & 30 days & 287.38 \\
& 90 days & 277.26 \\
Artificial weathering & 150 days & 278.92 \\
& $10 \mathrm{~h}$ & 283.57 \\
& $20 \mathrm{~h}$ & 287.87 \\
& $80 \mathrm{~h}$ & 292.84 \\
\hline
\end{tabular}


Amino Acid Analysis. Table 3 depicts amino acid contents of B.mori silk unexposed and exposed in natural aging 150 days and artificial accelerated aging $80 \mathrm{~h}$, respectively. Try is not detected owing to the acidic hydrolytic method. The contents of His, Lys, Tyr, Met and Cys obviously decline under natural and artificial weathering. At the same time, in the process of natural aging, the contents of His, Lys, Tyr, and Met dropped significantly higher than artificial aging.

Table 3 Amino acid contents of unaged B.mori silk sample and aged in natural and artificial weathering condition, respectively

\begin{tabular}{cccc}
\hline Amino acid & Unexposed sample $(\mathrm{mg})$ & Natural aging 150 days $(\%)$ & Artificial aging 80 hour (\%) \\
\hline Asp & 5.3389 & -45.22 & -32.17 \\
Thr & 2.5788 & -34.26 & -31.54 \\
Ser & 26.9654 & -25.28 & -32.32 \\
Glu & 4.5609 & -43.75 & -29.48 \\
Gly & 86.7019 & -21.32 & -32.46 \\
Ala & 66.0977 & -14.17 & -31.11 \\
Cys & 0.9072 & +61.23 & -14.09 \\
Val & 6.1395 & -22.31 & -31.33 \\
Met & 0.1011 & -42.73 & -88.62 \\
Ile & 2.0494 & -36.14 & -31.71 \\
Leu & 1.3756 & -32.13 & -37.73 \\
Tyr & 21.4625 & -75.21 & -37.86 \\
Phe & 2.7039 & -31.16 & -33.49 \\
Lys & 1.0867 & -53.52 & -33.26 \\
His & 0.7086 & -96.74 & -53.14 \\
Arg & 1.8952 & -44.64 & -33.52 \\
Pro & 1.1055 & -45.14 & -41.75 \\
\hline
\end{tabular}

Note: "+" indicate amino acid contents increasing; "-" indicate amino acid contents decreasing.

Under natural aging 150 days, the contents of each amino acid declined evidently especially His, Tyr, and Lys which dropped 96.74\%, 75.21\%, and 53.52\% respectively. However, the content of Cys increased $61.23 \%$. When B.mori silk was irradiated $80 \mathrm{~h}$ in artificial weathering, the contents of each amino acid all decreased especially Met, His, Pro, and Tyr which dropped 88.62\%, 53.14\%, 41.75\%, and $37.86 \%$, respectively.

As it can be seen in Table 3, the amino acid composition of B.mori silk unchanged before and after natural and artificial weathering, but the contents of each amino acid declined. The contents of Tyr and Phe were lower than unexposed samples. This indicates anti-ultraviolet performance of B.mori silk fabric itself declines because of the existence of benzene in Tyr and Phe; the contents of Asp and Glu were lower than unexposed samples, it demonstrates the characteristic peaks of amide I, and amide II, etc. disappear which is confirmed in FTIR analysis. In addition, the contents of those polar amino acids (e.g., Asp, Glu, Lys, Arg, His, and Tyr) decreased. These experimental results indicate the molecular structure and crystallinity have some changes in B.mori silk before and after natural and artificial aging. After further analysis, it confirms that the degradation of mechanical property and the disappearance of amide I, and amide II, etc. is due to the reduction of amino acid content caused.

\section{Conclusions}

In this work, the combination of several characterization techniques allowed to research the effect of UV radiation when B.mori silk fabric samples submitted to natural and artificial weathering.

According to the natural and artificial weathering test results, it can be concluded that yellowing phenomenon occurs preferentially on B.mori silk fabric. At the same time, yellowness index shows a rising trend with the extension of UV irradiation time. In addition, this surface phenomenon during natural and accelerated aging process affects mechanical property and amino acid contents.

The drastic decrease of breaking strength for B.mori silk fabric samples exposed to both type of weathering is due to conformation changes and molecular chemical bonds scission which is proved by FTIR analysis, thermal property, and amino acid analysis in this paper. 
For B.mori silk aging research, artificial weathering can be used to substitute for natural weathering for its weathering evaluation, which is helpful to understand the aging behavior and take measures to avoid aging and elongate its service life.

\section{References}

[1] H.P. Zhao, X.Q. Feng and H.J. Shi: Mater. Sci. Eng. C Vol. 27 (2007), p. 675-683

[2] T. Arai, G. Freddi and R. Innocenti and M. Tsukada: J. Appl. Polym. Sci. Vol. 91 (2004), p. 2383-2390

[3] J. Perez-Rigueiro, C. Viney, J. Liorca and M. Elices: J. Appl. Polym. Sci. Vol. 75 (2000), p. 1270-1277

[4] M. Tsukada, G. Freddi and N. Kasai: J. Polym. Sci. Part B Vol. 32 (1994), p. 1175-1182

[5] B.R. Das: The Open Textile Journal Vol. 3 (2010), p. 14-21

[6] R.M. Santos, G.L. Botelho and A.V. Machado: J. Appl. Polym. Sci. Vol. 116 (2010), p. 2005-2014

[7] V. Vassileva, S. Baltova and S. Handjieva: Polym. Degrad. Stab. Vol. 61 (1998), p. 367-373

[8] X.M. Zhang and S.X. Yuan: Chinese J. Chem. Vol. 28 (2010), p. 656-662

[9] M. Mondal, K. Trivedy and S.N. Kumar: Caspian J. Env. Sci. Vol. 5 (2007), p. 63-76

[10] D. Sargunamani and N. Selvakumar: J. Appl. Polym. Sci. Vol. 104 (2007), p. 147-155

[11] D. Sargunamani and N. Selvakumar: Polym. Degrad. Stab. Vol. 91 (2006), p. 2644-2653

[12] N.V. Bhat and G.S. Nadiger: J. Appl. Polym. Sci. Vol. 25 (1980), p. 921-932

[13] M. Tsukada, G. Freddi, M. Nagura, H. Ishikawa and N. Kasai: J. Appl. Polym. Sci. Vol. 46 (1992), p. 1945-1953

[14] J.E. Pickett, D.A. Gibson and M.M. Gardner: Polym. Degrad. Stab. Vol. 93 (2008), p. 1597-1606

[15] J.E. Pickett and J.R. Sargent: Polym. Degrad. Stab. Vol. 94 (2009), p. 189-195

[16] J.E. Pickett, D.A. Gibson, S.T. Rice and M.M. Gardner: Polym. Degrad. Stab. Vol. 93 (2008), p. 684-691

[17] M. Diepens and P. Gijsman: Polym. Degrad. Stab. Vol. 94 (2009), p. 34-38

[18] A. Heikkila, A. Tanskanen, P. Karha and K. Hanhi: Polym. Degrad. Stab. Vol. 92 (2007), p. 675-683

[19] J. Kim, X.M. Zhang and P. Wyeth: E-Preservation Sci. Vol. 5 (2008), p. 41-46

[20] V. Daniels and M. Leese: Restaurator Vol. 16 (1995), p. 45-63

[21] G.H. Wang, L.P. Sun, S.M. Ma and J.F. Zhou: Adv. Mater. Res. Vol. 175-176 (2011), p. 149-152

[22] ASTM Method D 1435 Standard practice for outdoor weathering of plastics. American Society for Testing and Materials (2005)

[23] GB/T 8427-2008 Textiles - Tests for color fastness - Color fastness to artificial light: Xenon arc fading lamp test. Standards Press for China (2009)

[24] S. Baltova, V. Vassileva and E. Valtcheva: Polym. Degrad. Stab. Vol. 60 (1998), p. 53-60

[25] M. Tsukada, T. Imai, G. Freddi, S. Lenka and N. Kasai: J. Appl. Polym. Sci. Vol. 69 (1998), p. 239-246

[26] J. Magoshi and S. Nakamura: J. Appl. Polym. Sci. Vol. 19 (1975), p. 1013-1015

[27] A. Motta, L. Fambri and C. Migliaresi: Macromol. Chem. Phys. Vol. 203 (2002), p. 1658-1665

[28] J. Magoshi, M. Mizuide, Y. Magoshi, K. Takahashi, M. Kubo and S. Nakamura: J. Polym. Sci. Polym. Phys. Edi. Vol. 17 (1979), p. 515-520

[29] Y. Gotoh, M. Tsukada, T. Baba and N. Minoura: Polymer Vol. 38 (1997), p. 487-490

[30] G. Freddi, G. Pessina and M. Tsukada: Int. J. Bio. Macromol. Vol. 24 (1999), p. 251-263

[31] M. Tsukada, Y. Gotoh, M. Nagura, N. Minoura, N. Kasai and G. Freddi: J. Polym. Sci. Part B Polym. Phys. Vol. 32 (1994), p. 961-968

[32] S. Nakamura, Y. Saegusa, Y. Yamaguchi, J. Magoshi and S. Kamiyama: J. Appl. Polym. Sci. Vol. 31 (1986), p. 955-956 